\title{
Vesicocervical Fistula Post Emergency Repeat Caesarean Delivery
}

\author{
Rekha Poudel, Ganesh Dangal, Aruna Karki, Hema Pradhan, Ranjana Shrestha, Kabin Bhattachan, \\ Nishma Bajracharya, Kenusha Devi Tiwari
}

Department of Obstetrics and Gynecology, Kathmandu Model Hospital, Nepal

DOI: http://dx.doi.org/10.3126/njog.v13i2.21702

\begin{abstract}
Urogenital fistula is an abnormal communication between the urinary tract and genital tract at different levels, vesicocervical fistula being rare. It has been the consequence of poor obstetric care in developing world and iatrogenic following gynecologic surgeries in developed world. Diagnosis is mainly done by clinical examination, conventional dye test with methylene blue and imaging studies and cystoscopy, if required. Though prevention is better than cure, early detection followed by transurethral bladder drainage and surgical correction via vaginal or abdominal approach is the mainstay of treatment. A 30 years postnatal mother was referred to our centre with complaints of continuous involuntary leakage of urine per vaginum following emergency repeat caesarean delivery done six weeks back. There was pooling of urine over Sim's speculum and dye test was positive. Under spinal anesthesia, vesicocervical fistula was repaired vaginally and patient was kept on Foley's catheter for three weeks. Dye test performed at the end was negative. She went home dry and continent. We present here a rare case of successful repair of vesicocervial fistula post emergency repeat caesarean delivery.
\end{abstract}

Keywords: dye test, repeat cesarean delivery, urogenital fistula, vesicocervical fistula.

\section{INTRODUCTION}

An obstetric fistula is defined as an "abnormal opening between a woman's vagina and bladder and/or rectum through which her urine and/or faeces continually leak." ${ }^{\prime 1}$ Vesicovaginal fistulas are most common, while vesicocervical is rare, though its incidence is increasing due to increasing rate of cesarean deliveries. ${ }^{2}$ Estimates suggest that at least 3 million women in poor countries have unrepaired vesicovaginal fistulas, and that 30000-130000 new cases develop each year in Africa alone. ${ }^{3}$ Iatrogenic postoperative VVF is most common in developed countries, compared to mainly obstetric trauma in developing countries. ${ }^{4}$

\section{CASE REPORT}

A 30 years postnatal woman referred from Sarlahi district presented at the Obstetrics and Gynaecology Out-patients with complaints of involuntary and continuous urinary leakage per vaginum since six weeks i.e. six days following her emergency repeat cesarean section done for previous cesarean section in labour with scar tenderness. Details of intraoperative findings could not be gathered. At our center, general physical revealed her poor nutritional

\section{CORRESPONDENCE}

Dr Rekha Poudel

Department of Obstetrics and Gynecology, Kathmandu Model Hospital, Nepal

Email: drrekhapoudel@gmail.com

Phone: +977- 9803721075 status. Abdomen was soft and nontender. There was pooling of urine over Sim's speculum. Anterior lip of cervix was pulled up and poorly visualized. Fistulous opening couldn't be appreciated. Dye test was done with Methylene blue and it was positive. Ultrasound pelvis scan was normal with no hydronephrosis. Urine routine examination showed plenty of pus cells and urine culture showed E. coli isolated. She was admitted and treated with parenteral antibiotics prior to surgical repair.

Under spinal anesthesia, evaluation was done which showed positive dye test, anterior lip of cervix being pulled up, fragile tissue and intracervical fistulous opening of around $2 \mathrm{~cm}$. Then, wide dissection was done. Fistulous tract was identified communicating with the urinary bladder via the intracervical opening. The fistulous tract was excised, tissue plane was mobilized, margins freshened and edges approximated in layers with Vicryl 2-0 suture. Dye test following it was positive. Then, the edges were re-strengthened in additional layer followed by the closure of cervical defect. Repeated dye test was then negative. Tight vaginal pack was placed which was removed after 24 hours. 16 F Foleys catheter was continued for three weeks. Antibiotics was continued for one week. During the period, patient was dry. She drank adequately and urine drained properly. Dye test performed at three weeks was negative and Foleys catheter was removed. She was discharged home dry and continent. She is yet to come for her one week follow up post discharge from the hospital. 


\section{COMMENTS}

A vesicocervical fistula is an abnormal fistulous tract between the cervix and urinary bladder, causing continuous loss of urine via cervix and vagina. It is rare covering only $1-4 \%$ of all urogenital fistulas, most of which are complications of cesarean section; other possible causes being rupture of lower uterine segment and bladder due to traumatic forceps delivery, bladder tuberculosis and a perforation of IUCD into bladder. ${ }^{5}$ Its incidence has also been increasing due to increasing rates of lower segment cesarean section with risk of bladder damage which doubles in repeat cesarean section. ${ }^{6}$ The possible cause in this case could be rupture of the previous lower segment scar with extension of the tear and difficulty in repair at a small center with less surgical expertise.

During lower segment cesarean section, the bladder base may be torn, rendered ischaemic or included in a suture to result in a fistula which usually communicates to the uterus or cervix. Bladder may also be injured during delivery of large fetal head if there is no adequate mobilization of bladder laterally and inferiorly. ${ }^{6}$ Lower uterine scar to be pointing upward as each end, use of compression on bleeding area for attaining hemostasis instead of blind haemostatic sutures and careful approach to parietal and visceral peritoneum with gentle dissection and separation of bladder from the lower uterine segment are various recommendations been put forward. ${ }^{7}$ Early detection of the fistula is important followed by conservative transurethral bladder drainage for three weeks to three months, by which small vesicovaginal fistula might close. The success rate of repair within 1-8 weeks of injury is $80 \%$ while with standard delayed method is $95-98 \%$. Mainstay of treatment for vesicocervical fistula is conservative management. Surgical repair, if required is preferred via abdominal approach. Keys to the closure of vesicocervical fistula include identification of fistula site, wide mobilization of tissue planes, excision of fistulous tract, tension free closure in multiple layers and closure of the cervical fistulous opening followed by continuation of Foley's catheterization for 14-21 days.

\section{CONCLUSIONS}

Urogenital fistula has been one of the notable causes for the postpartum morbidity, thus timely access to advanced emergency obstetric services is a must in developing countries. Prevention is better than cure, so proper surgical skills and early identification and repair during the surgery itself is unlikely to cause fistula.

\section{REFERENCES}

1. Adler AJ, Ronsmans C, Calvert C, Filippi V. Estimating the prevalence of obstetric fistula: a systematic review and metaanalysis. BMC pregnancy and childbirth. 2013;13(1):246

2. Berek JS. Lower Urinary Tract Disorders. In: Menefee SA, Nygaard I, editors. Berek and Novak's Gynecology.15th edn. New Delhi: Wolters Kluwer; 2015.p.862-905.

3. Wall LL. Obstetric vesicovaginal fistula as an internationa public-health problem. The Lancet. 2006;368(9542):1201-9.

4. Ghoniem GM, Warda HA. The management of genitourinary fistula in the third millennium. Arab J Urol. 2014;12(2):97105 .
5. Azim AK. Vesicocervical Fistula: An Uncommon Presentation. BMJ. 2011;40(1):51-2.

6. Thobbi VA, Suguna V, Kamdod S, Patil SB. Post Repeat Lower Segment Caesarean Section Cervicovesical Fistula. Al Ameen J Med Sci. 2008;1(2):133-5.

7. Rajasekar D, Hall M. Urinary tract injuries during obstetric intervention. Int J Gynaecol Obstet. 1997;104(6):731-4. 